Fitriah, Perlindungan Hukum Terhadap Pasien Badan Penyelenggara Jaminan Sosial dalam Mendapatkan Pelayanan Kesehatan, Halaman 223-233

\title{
PERLINDUNGAN HUKUM TERHADAP PASIEN PESERTA BADAN PENYELENGGARA JAMINAN SOSIAL DALAM MENDAPATKAN PELAYANAN KESEHATAN
}

\author{
Fitriah \\ Fakultas Hukum Universitas Palembang \\ E-mail: Fitriah241171@yahoo.com
}

\begin{abstract}
The legal protection of patients' rights participating in the Health Social Security Administering Board (BPJS), in obtaining government health services, issued Law Number 24 of 2011 stipulating two State-Owned Enterprises namely PT Askes (Persero) and PT Jamsostek (Persero) to be changed in form became a Public Service Agency to carry out five programs mandated by Law Number 40 of 2004, namely the Health Insurance program for Health BPJS and other programs submitted to BPJS Employment. Hospitals in providing health services to BPJS participants are constrained by the unmet fulfillment of facilities and infrastructure in accordance with applicable standards and the non-fulfillment / availability of consumable medicines and medical materials needed. The provision of Article 49 of Law Number 24 Year 2011 states that for those parties who feel disadvantaged and their complaints cannot be resolved by the quality control unit, dispute resolution can be done through a mediation mechanism. Settlement agreements through mediation must be in writing, final and binding. In the case of complaints that cannot be resolved by controlling the quality of services and handling complaints by participants through the unfinished mechanism of dispute resolution, it can be submitted to the District Court in the area where the applicant lives.
\end{abstract}

Keywords: Health Social Security Organizing Agency

\begin{abstract}
Abstrak
Perlindungan hukum hak-hak pasien peserta Badan Penyelenggara Jaminan Sosial (BPJS) kesehatan dalam mendapatkan pelayanan kesehatan, pemerintah mengeluarkan UndangUndang Nomor 24 Tahun 2011 yang menetapkan dua Badan Usaha Milik Negara yaitu PT Askes (Persero) dan PT Jamsostek (Persero) diubah menjadi Badan Layanan Publik untuk melaksanakan lima program yang diamanatkan Undang-Undang Nomor 40 Tahun 2004 yaitu program Jaminan Kesehatan bagi BPJS Kesehatan dan program lainnya diserahkan ke BPJS Ketenagakerjaan. Rumah Sakit dalam memberikan pelayanan kesehatan kepada peserta BPJS terkendala pada belum terpenuhinya sarana dan prasarana sesuai dengan standar yang berlaku. Masih terbatasnya ketersediaan obat dan bahan medis habis pakai. Ketentuan Pasal 49 Undang-Undang Nomor 24 Tahun 2011 menyebutkan bahwa bagi para pihak yang merasa di rugikan dan pengaduannya belum dapat diselesaikan oleh unit pengendalian mutu, maka penyelesaian sengketa dapat dilakukan melalui mekanisme mediasi yang dibuat secara tertulis, bersifat final dan mengikat. Pada pengaduan tidak dapat diselesaikan oleh pengendalian mutu pelayanan dan penanganan pengaduan peserta melalui mekanisme mediasi, maka dapat diajukan ke Pengadilan Negeri di wilayah tempat tinggal pemohon.
\end{abstract}

Kata Kunci: Badan Penyelenggara Jaminan Sosial Kesehatan

I. PENDAHULUAN
Undang-Undang Nomor 24 Tahun

2011 tentang Badan Penyelenggara 
Fitriah, Perlindungan Hukum Terhadap Pasien Badan Penyelenggara Jaminan Sosial dalam Mendapatkan Pelayanan Kesehatan, Halaman 223-233

Jaminan Sosial (BPJS) menetapkan bahwa Jaminan Sosial Nasional akan diselenggarakan oleh BPJS, yang terdiri atas BPJS Kesehatan dan BPJS Ketenagakerjaan. Khusus untuk Jaminan Kesehatan Nasional (JKN) akan diselenggarakan oleh BPJS Kesehatan. Implementasinya dimulai 1 Januari 2014. Secara operasional, pelaksanaan JKN dituangkan dalam Peraturan Pemerintah dan Peraturan Presiden, antara lain Peraturan Pemerintah Nomor 101 Tahun 2012 tentang Penerima Bantuan Iuran (PBI); Peraturan Presiden Nomor 12 Tahun 2013 tentang Jaminan Kesehatan. Pembentukan UndangUndang tentang Badan Penyelenggara Jaminan Sosial merupakan pelaksanaan Undang-Undang Nomor 40 Tahun 2004 tentang Sistem Jaminan Sosial Nasional. Undang-Undang ini merupakan pelaksanaan dari Pasal 5 ayat (1) dan Pasal 52 Undang-Undang Nomor 40 Tahun 2004 tentang Sistem Jaminan Sosial Nasional yang mengamanatkan pembentukan Badan Penyelenggara Jaminan Sosial dan transformasi kelembagaan PT Askes (Persero), PT Jamsostek (Persero), PT TASPEN (Persero), dan PT ASABRI (Persero) menjadi Badan Penyelenggara Jaminan Sosial (BPJS). Dengan Undang-Undang ini dibentuk 2 (dua) BPJS, yaitu BPJS Kesehatan dan BPJS Ketenagakerjaan. BPJS Kesehatan menyelenggarakan program jaminan kesehatan dan BPJS Ketenagakerjaan menyelenggarakan program jaminan kecelakaan kerja, jaminan hari tua, jaminan pensiun, dan jaminan kematian. Dengan terbentuknya kedua BPJS tersebut jangkauan kepesertaan program jaminan social akan diperluas secara bertahap. Karena kesehatan sebagai hak setiap manusia, dan kewajiban negara memenuhi hak itu terutama pada situasi bahwa tidak setiap orang mempunyai kesempatan yang sama untuk menikmati haknya itu, merupakan isi keadilan. ${ }^{1}$

Guna mendukung pelaksanaan tersebut, Kementerian Kesehatan tengah mengupayakan penyiapan pelaksanaan JKN yang meliputi penyiapan infrastruktur pelayanan transformasi kelembagaan, program penghitungan iuran regulasi berupa Peraturan Menteri, yang akan menjadi payung hukum untuk mengatur antara lain pelayanan kesehatan, pelayanan kesehatan tingkat pertama, dan pelayanan kesehatan rujukan tingkat lanjutan. Peraturan Menteri juga akan mengatur jenis dan

1 Titon Slamet Kurnia, Hak Atas Derajat Kesehatan Optimal Sebagai HAM di Indonesia, Bandung: Alumni, 2007, hlm. 2. 
Fitriah, Perlindungan Hukum Terhadap Pasien Badan Penyelenggara Jaminan Sosial dalam Mendapatkan Pelayanan Kesehatan, Halaman 223-233

plafon harga alat bantu kesehatan dan pelayanan obat dan bahan medis habis pakai untuk Peserta Jaminan Kesehatan Nasional. Badan kesehatan dunia (WHO) telah menetapkan bahwa kesehatan merupakan investasi, hak, dan kewajiban setiap manusia. Kutipan tersebut juga tertuang dalam Pasal 28 ayat (3) Undang-Undang Dasar 1945 selanjutnya disingkat dengan (UUD NRI) dan Undang-Undang Nomor 36 Tahun 2009 tentang Kesehatan selanjutnya disingkat dengan (UUK), menetapkan bahwa setiap orang berhak mendapatkan pelayanan kesehatan. Karena itu setiap individu, keluarga dan masyarakat berhak memperoleh perlindungan terhadap kesehatannya, dan negara bertanggungjawab mengatur agar terpenuhi hak hidup sehat bagi penduduknya termasuk bagi masyarakat miskin dan tidak mampu. Kenyataan yang terjadi, derajat kesehatan masyarakat miskin yang masih rendah tersebut diakibatkan karena sulitnya akses terhadap pelayanan kesehatan yang dipengaruhi oleh berbagai faktor seperti tidak adanya kemampuan secara ekonomi dikarenakan biaya kesehatan memang mahal. Derajat kesehatan yang rendah berpengaruh terhadap rendahnya produktifitas kerja yang pada akhirnya menjadi beban masyarakat dan pemerintah.

Asuransi kesehatan atau jaminan pemeliharaan kesehatan adalah upaya untuk menciptakan suatu riskpooling, yaitu mengalihkan risiko pribadi menjadi risiko kelompok sehingga terjadi risk sharing. Dalam asuransi kesehatan biayanya dipikul bersama oleh masyarakat melalui sistem kontribusi yang dilakukan secara pra upaya. Tujuan asuransi kesehatan adalah meningkatkan pelayanan pemeliharaan kesehatan bagi peserta dan anggota keluarganya. Asuransi kesehatan juga bertujuan memberikan bantuan kepada peserta dalam membiayai pemeliharaan kesehatannya. $^{2}$

Bentuk pokok asuransi kesehatan terdiri dari tiga pihak (third party) yang saling berhubungan, yaitu: ${ }^{3}$

1. Tertanggung/peserta, yang dimaksud tertanggung/peserta yang terdaftar sebagai anggota, membayar iuran (premi) sejumlah dengan mekanisme tertentu. Dalam asuransi sosial ini yang menjadi peserta adalah Pegawai Negeri Sipil, Penerima Pensiunan, TNI/Polri, Veteran dan Perintis Kemerdekaan

2 Kertonegoro, S. Hukum Asuransi Indonesia, Bandung: PT. Citra Aditya Bakti. 1999, hlm. 12. 3 Sendra Ketut, Konsep dan Penerapan Asuransi, Yogyakarta: PPM, 2004, hlm. 34. 
Fitriah, Perlindungan Hukum Terhadap Pasien Badan Penyelenggara Jaminan Sosial dalam Mendapatkan Pelayanan Kesehatan, Halaman 223-233

beserta anggota keluarganya berdasarkan Peraturan Pemerintah Nomor 69 Tahun 1991.

2. Penanggung/badan asuransi, yang dimaksud penanggung atau badan asuransi (health insurance institutional) adalah yang bertanggung jawab mengumpulkan dan mengelola iuran serta membayar biaya kesehatan yang dibutuhkan peserta.

3. Pemberi Pelayanan Kesehatan, yang dimaksud dengan pemberi pelayanan kesehatan (health provider) adalah yang bertanggung jawab menyediakan pelayanan kesehatan bagi peserta dan untuk itu mendapatkan imbalan jasa dari badan asuransi.

Permasalahan yang akan diteliti adalah Bagaimanakah perlindungan hukum terhadap peserta BPJS kesehatan dalam mendapatkan pelayanan kesehatan menurut UU nomor 24 tahun 2011 serta kendala yang dihadapi rumah sakit dalam memberikan pelayanan kesehatan kepada peserta BPJS.

Dalam penelitian ini jenis penelitian yang digunakan adalah jenis penelitian yuridis normatif, yaitu penelitian yang dilakukan pada peraturan-peraturan yang tertulis yang berkaitan dengan masalah perlindungan hukum terhadap peserta BPJS kesehatan dalam mendapatkan pelayanan kesehatan menurut UndangUndang Nomor 24 Tahun 2011.

\section{PEMBAHASAN}

Pasien adalah orang yang sedang menderita penyakit atau gangguan badaniah/rohaniah yang perlu ditolong agar lekas sembuh dan berfungsi kembali melakukan kegiatannya sebagai salah satu anggota masyarakat. ${ }^{4}$ Menurut Kamus Besar Bahasa Indonesia, pasien adalah orang sakit (yang dirawat dokter), penderita (sakit). Dalam pasal 1 angka 10 Undang-Undang Nomor 29 Tahun 2004 tentang Praktik Kedokteran, Pasien adalah setiap orang yang melakukan konsultasi masalah kesehatannya untuk memperoleh pelayanan kesehatan yang diperlukan baik secara langsung maupun tidak langsung kepada dokter atau dokter gigi. Menurut M. Sofyan Lubis bahwa : Pasien secara yuridis tidak dapat diidentikan dengan konsumen, hal ini karena hubungan yang terjadi diantara mereka bukan merupakan hubungan jual beli yang diatur dalam KUHPerdata dan KUHD, melainkan hubungan antara dokter dengan pasien hanya merupakan bentuk perikatan medik, yaitu perjanjian "usaha" (inspanning verbintenis)

\footnotetext{
${ }^{4}$ Amri Amir, Bunga Rampai Hukum Kesehatan, Medan: Woya Medika, 1997, hlm. 17.
} 
Fitriah, Perlindungan Hukum Terhadap Pasien Badan Penyelenggara Jaminan Sosial dalam Mendapatkan Pelayanan Kesehatan, Halaman 223-233

tepatnya perjanjian usaha kesembuhan (teraupetik), bukan merupakan perikatan medik "hasil" (resultaat verbintenis), disamping itu profesi dokter dalam etika kedokteran masih berpegang pada prinsip "pengabdian dan kemanusiaan" sehingga sukit disamakan antara pasien dengan konsumen pada umumnya. ${ }^{5}$

Konsumen memang tidak sekedar pembeli (buyer atau koper) tetapi semua orang (perorangan atau badan usaha) yang mengkonsumsi jasa dan/atau barang. Jadi, yang paling penting terjadinya suatu transaksi konsumen (consumer transaction) berupa peralihan barang dan/atau jasa, termasuk peralihan kenikmatan dalam menggunakannya. ${ }^{6}$ Jika dilihat dari hubungan antara pasien dan tenaga kesehatan, maka terjadi peralihan jasa. Pasien merupakan pengguna jasa layanan kesehatan yang diberikan oleh tenaga kesehatan. Setalah terjadi peralihan jasa, maka setelah itu akan terjadi transaksi ekonomi baik secara langsung maupu tidak langsung yaitu pembayaran atas yang telah diperoleh.

\footnotetext{
5 Sofyan Lubis, Mengenal Hak Konsumen dan Pasien, Yogyakarta: Pustaka Yustisia, 2009, hlm. 38.

6 Celina Tri Siwi Kristiyanti, Hukum

Perlindungan Konsumen, Jakarta: Sinar Grafika, 2008, hlm. 2.
}

Selanjutnya dalam pasal 1 angka 3 Undang-undang Perlindungan Konsumen, dijelaskan bahwa jasa adalah setiap layanan yang berbentuk pekerjaan atau prestasi yang disediakan bagi masyarakat untuk dimanfaatkan oleh konsumen. Pengertian “disediakan bagi masyarakat menunjukan bahwa jasa itu harus ditawarkan kepada masyarakat. Artinya lebih dari satu orang. Jika demikian halnya, layanan yang bersifat khusus (tertutup) dan individual, tidak mencakup dalam pengertian tersebut. ${ }^{7}$

BPJS (Badan Penyelenggara Jaminan Sosial) adalah badan hukum yang dibentuk untuk menyelenggarakan program jaminan sosial. BPJS merupakanBadan Usaha Milik Negara (BUMN) yang ditugaskan khusus oleh pemerintah untuk menyelenggarakan program jaminan kesehatan bagi seluruh penduduk Indonesia termasuk orang asing yang berkerja paling singkat 6 (enam) bulan di Indonesia. BPJS bertanggung jawab kepada presiden. Berdasarkan Undang-Undang Republik Indonesia Nomor 24 Tahun 2011 tentang Badan Penyelenggara Jaminan Sosial pasal 5 ayat (2), BPJS terbagi atas dua yaitu:

\footnotetext{
${ }^{7}$ Ahmad Miru dan Sutarman Yodo, Hukum Perlindungan Konsumen, Jakarta: PT. Raja GrafindoPersada, 2007, hlm. 14.
} 
Fitriah, Perlindungan Hukum Terhadap Pasien Badan Penyelenggara Jaminan Sosial dalam Mendapatkan Pelayanan Kesehatan, Halaman 223-233

a. BPJS Kesehatan

b. BPJS Ketenagakerjaan

BPJS Kesehatan berfungsi menyelenggarakan program jaminan kesehatan, sedangkan BPJS Ketenagakerjaan berfungsi menyelenggarakan program jaminan kecelakaan kerja, program jaminan kematian, program jaminan pensiun, dan program jaminan hari tua. ${ }^{8}$ Pembayaran Iuran BPJS Kesehatan paling lambat dilakukan tanggal 10 setiap bulanya. Apabila peserta BPJS melakukan keterlambatan dalam pembayaran akan dikenakan denda. Namum jika keterlambatan pembayaran tersebut lebi dari satu bulan, maka peserta BPJS Kesehatan akan diberhentikan sementara.

Dalam melaksanakan kewenangannya, BPJS mempunyai hak untuk:

a. Memperoleh dana operasional untuk penyelenggaraan program yang bersumber dari dana jaminan sosial dan atau sumber lainnya.

b. Memperoleh hasil monitoring dan evaluasi penyelenggaraan program

\footnotetext{
8 Pasal 9 ayat (1) Undang-Undang Negara Republik Indonesia Nomor 24 Tahun 2001 tentang Badan Penyelenggara Jaminan Sosial.
}

jaminan sosial dan DSJN setiap 6 bulan.

Dalam melaksanakan tugasnya, BPJS berkewajiban untuk:

a. Memberikan nomor identitas tunggal kepada peserta

b. Mengembangkan aset dana jaminan sosial dan aset BPJS untuk sebesarbesarnya kepentingan peserta

c. Memberikan informasi melalui media massa cetak dan elektronik mengenai kinerja, kondisi keuangan, seta kekayaan dan hasil pengembangannya

d. Memberikan manfaat kepada seluruh peserta sesuai dengan undang-undang SJSN

e. Memberi informasi kepada peserta mengenai hak dan kewajiban untuk mengikuti ketentuan yang berlaku

f. Memberi informasi kepada peserta mengenai prosedur untuk mendapatkan hak dan memenuhi kewajibannya

g. Memberikan informasi kepada peserta mengenai saldo jaminan hari tua dan pengembanganny satu kali dalan satu tahun

h. Memberikan informasi kepada peserta mengenai hak pensiun sekali dalam setahun. 
Fitriah, Perlindungan Hukum Terhadap Pasien Badan Penyelenggara Jaminan Sosial dalam Mendapatkan Pelayanan Kesehatan, Halaman 223-233

i. Membentuk cadangan teknis sesuai dengan standar praktikum aktuaria yang lazim dan berlaku umum

j. Melakukan pembukuan sesua dengan standar akuntansi yang berlaku dalam penyelenggaraan jaminan sosial

k. Melaporkan pelaksanaan setiap program, termasuk kondisi keuangan, secara berkala 6 bulan sekali kepada presiden dengan tebusan kepada DSJN.

Pelayanan umum (public services) memang sarat dengan berbagai masalah apalagi wilayah jangkauannya sendiri sangat luas meliputi sektor profit ataupun non profit. Sedemikian luas jangkauannya sehingga tidak mudah mendeskripsikan persepsi masyarakat terhadap pelayanan umum. ${ }^{9}$ Sebagai unit terbesar pelayanan kesehatan, rumah sakit memiliki dua fungsi, yaitu kuratif dan preventif. Fungsi kuratif lebih bertitik berat pada penyembuhan pasien sakit. Fungsi preventif membawa konsekuensi misi pelayanan kesehatan adalah meningkatkan daya tahan manusia terhadap ancaman penyakit, misalnya, lewat Program Imunisasi Nasional (PIN).

${ }^{9}$ Yusuf Shofie. Perlindungan Konsumen dan Instrumen-Instrumen Hukumnya, Bandung: Citra Aditya Bakti, 2009, hlm. 207.
Keberhasilan upaya kesehatan tergantung pada ketersediaan sumber daya kesehatan yang berupa tenaga, sarana, dan prasarana dalam jumlah dan mutu yang memadai. Rumah sakit merupakan salah satu sarana kesehatan yang diselenggarakan baik oleh pemerintah maupun masyarakat. ${ }^{10}$ Oleh sebab itu, setiap orang berhak mendapatkan pelayanan kesehatan dan derajat kesehatan yang setinggitingginya. ${ }^{11}$ Karena hak adalah segala sesuatu yang harus didapatkan oleh setiap orang yang telah ada sejak lahir bahkan sebelum lahir. Hak merupakan sesuatu yang pasti dimiliki setiap orang, baik haknya sebagai bagian dari suatu sistem masyarakat bahkan haknya sebagai manusia. ${ }^{12}$

Di dalam hukum, hak adalah kepentingan hukum yang dilindungi oleh hukum. Kepentingan sendiri berarti tuntutan yang diharapkan untuk dipenuhi. Sehingga dapat dikatakan bahwa hak adalah suatu tuntutan yang pemenuhannya

10 Sri Praptianingsih, Kedudukan Hukum Perawat Dalam Upaya Pelayanan Kesehatan di Rumah Sakit, Jakarta: PT.RajaGrafindo Persada, Jakarta, 2006, hlm. 12.

${ }^{11}$ Hendrik, Etika dan Hukum Kesehatan, Jakarta, 2013, hlm. 37.

${ }^{12}$ Muhamad Sais Is, Pengantar Ilmu Hukum, Jakarta: PT. Kharisma Putra Utama, 2015, hlm.102. 
Fitriah, Perlindungan Hukum Terhadap Pasien Badan Penyelenggara Jaminan Sosial dalam Mendapatkan Pelayanan Kesehatan, Halaman 223-233

dilindungi oleh hukum. ${ }^{13}$ Hak pasien merupakan hak asasi yang bersumber dari hak dasar individu dalam bidang kesehatan. Dalam hubungan antara dokter dan pasien, secara relative pasien berada dalam posisi yang lebih lemah. Kekurang mampuan pasien untuk membela kepentingannya dalam situasi pelayanan kesehatan menyebabkan timbulnya kebutuhan untuk mempermasalahkan hak-hak pasien dalam menghadapi para professional kesehatan.

Hak-hak yang dimiliki pasien harus diseimbangkan dengan kewajibannya. Maka masyarakat atau pasien yang baik akan memenuhi kewajibannya setelah haknya dipenuhi oleh petugas kesehatan atau dokter yang melayaninya. ${ }^{14}$ Dalam pasal 53 Undang-Undang Nomor 29 Tahun 2004 tentang Praktik Kedokteran, pasien dalam menerima pelayanan dalam praktik kedokteran, mempunyai kewajiban:

a. Memberi informasi yang lengkap dan jujur tentang masalah kesehatannya.

b. Mematuhi nasihat dan petunjuk dokter atau dokter gigi.

13 Sudikno Mertokusumo, Mengenal Hukum Suatu Pengantar, Yogyakarta: Liberty,1985, hlm. 2.

14 Soekidjo Notoatmodjo, Etika Hukum dan Kesehatan, Jakarta: PT Rineka Cipta, 2010, hlm. 175 . c. Mematuhi ketentuan yang berlaku di sarana pelayanan kesehatan, dan

d. Memberi imbalan jasa atas pelayanan yang diterima.

Pengaturan mengenai perlindungan hukum pasien ini tersebar dalam berbagai peraturan perundang-undangan. Di dalam Perjanjian yang dikenal dalam bidang pelayanan jasa kesehatan adalah perjanjian teraupetik. Perjanjian teraupetik adalah perjanjian antara dokter dengan pasien, berupa hubungan hukum yang melahirkan hak dan kewajiban bagi kedua belah pihak. Adapun objek dari perjanjian itu adalah upaya yang dilakukan dokter untuk menyembuhkan pasien. ${ }^{15}$ Jadi, hubungan yang dibangun antara dokter dengan pasien dalam pandangan hukum perdata adalah perjanjian. Untuk sahnya suatu perjanjian ini diatur dalam Pasal 1320 KUHPerdata.

Berdasarkan perjanjian teraupetik, pelanggaran yang dapat terjadi adalah perbuatan wanprestasi dan perbuatan melawan hukum (onrechtmatige daad). Wanprestasi (ingkar janji) dalam pelayanan kesehatan adalah suatu keadaan yang mana pelayan kesehatan tidak melakukan kewajibannya bukan

15 Bahder Johan Nasution, Hukum Kesehatan Pertanggungjawaban Dokter, Jakarta: Rineka Cipta, 2005, hlm. 11. 
Fitriah, Perlindungan Hukum Terhadap Pasien Badan Penyelenggara Jaminan Sosial dalam Mendapatkan Pelayanan Kesehatan, Halaman 223-233

karena keadaan memaksa (overmacht). Suatu perbuatan dapat dapat dikatakan wanprestasi apabila: ${ }^{16}$

a. Tidak melakukan apa yang disanggupi akan dilakukan.

b. Melaksanakan apa yang diperjanjikan, tetapi tidak sebagaimana dijanjikan.

c. Melakukan apa yang dijanjikan tetapi terlambat.

d. Melakukan sesuatu yang menurut perjanjian tidak boleh dilakukan.

Untuk perlindungan hukum terkait dengan peserta BPJS kesehatan dalam mendapatkan pelayanan kesehatan pemerintah mengeluarkan UndangUndang RI Nomor 24 Tahun 2011 yang menetapkan dua BUMN yaitu PT Askes (persero) dan PT Jamsostek (Persero) dirubah bentuk menjadi Badan Layanan Publik untuk melaksanakan lima program yang diamanatkan UndangUndang Nomor 40 Tahun 2004 yaitu program Jaminan Kesehatan bagi BPJS Kesehatan dan program lainnya diserahkan ke BPJS Ketenagakerjaan. Pemerintah melalui Menteri Kesehatan telah menetapkan beberapa peraturan yang mengatur tentang pelaksanaan program BPJS kesehatan baik itu tentang tarif maupun prosedur dalam

\footnotetext{
${ }^{16}$ Subekti, Hukum Perjanjian, Bandung: PT Intermasa, 1990, hlm. 45.
}

mendapatkan pelayanan kesehatan. Pada peraturan tersebut agar peserta tidak dipungut bila memanfaatkan haknya untuk mendapatkan pelayanan. Sementara BPJS kesehatan telah menyiapkan petugas disetiap Rumah Sakit agar dapat mengawal dan mendampingi serta memberikan pelayanan kepada peserta dalam memanfaatkan haknya untuk berobat di fasilitas kesehatan yang ditunjuk.

Adanya penerapan JKN ini, diharapkan tidak ada lagi masyarakat Indonesia, khususnya masyarakat miskin yang tidak berobat kefasilitas pelayanan kesehatan ketika sakit karena tidak memiliki biaya. Pelaksanaan JKN pada dasarnya merupakan amanat UU Sistem Jaminan Sosial Nasional (SJSN) dan Undang-Undang Nomor 24 Tahun 2011 tentang Badan Penyelenggara Jaminan Sosial (UU BPJS), dimana jaminan kesehatan adalah jaminan berupa perlindungan kesehatan agar peserta memperoleh manfaat pemeliharaan kesehatan dan perlindungan dalam memenuhi kebutuhan dasar kesehatan yang diberikan kepada setiap orang yang telah membayar iuran atau iurannya dibayar oleh pemerintah.

Kendala-kendala yang dihadapi BPJS Kesehatan dalam memberikan 
Fitriah, Perlindungan Hukum Terhadap Pasien Badan Penyelenggara Jaminan Sosial dalam Mendapatkan Pelayanan Kesehatan, Halaman 223-233

pelayanan kesehatan kepada peserta BPJS Kesehatan yaitu masih sering dikeluhkan oleh peserta adanya tarikan atau obat disuruh diambil diluar rumah sakit dengan biaya pribadi, hal ini karena di beberapa rumah sakit masih terjadi kendala dalam pengadaan obatnya. Kendala-kendala yang dihadapi Rumah Sakit dalam memberikan pelayanan kesehatan kepada peserta BPJS adalah :

1. Masih belum terpenuhinya sarana dan prasarana sesuai dengan standar yang berlaku seperti ruangan, kelas, tempat tidur, alat kesehatan dan pelayanan penunjang lainnya karena keterbatasan dana yang ada.

2. Masih belum terpenuhinya/tersedianya obat dan bahan medis habis pakai yang dibutuhkan. Hal yang sering dikeluhkan pasien lainnya yaitu masih adanya obat-obatan yang tidak tersedia di apotek Rumah Sakit dan tidak ditanggung BPJS sehingga obat harus tetap membeli di apotek luar.

Oleh karena itu, peserta BPJS dan penyelenggara BPJS tidak dipungkiri dapat menimbulkan perselisihan bagi kedua belah pihak. Penyelenggara sengketa dapat dilakukan baik melalui pengadilan maupun di luiar pengadilan. Dalam hal pengaduan tidak dapat diselesaikan oleh pengendalian mutu pelayanan dan penanganan pengaduan peserta melalui mekanisme tidak dapat terlaksana penyelesaian sengketa dapat diajukan ke Penga. Namun demikian penyelesaian sengketa di usahakan semaksimal mungkin dapat diselesaikan di luar pengadian untuk mendapatkan penyelesaian yang sama-sama menguntungkan kedua belah pihak.

\section{PENUTUP}

Perlindungan hukum yang terkait dengan hak-hak pasien peserta BPJS kesehatan, dalam mendapatkan pelayanan kesehatan, pemerintah telah mengeluarkan Undang-Undang RI Nomor 24 Tahun 2011 yang menetapkan dua BUMN yaitu PT Askes (persero) dan PT Jamsostek (Persero) dirubah bentuk menjadi Badan Layanan Publik untuk melaksanakan lima program yang diamanatkan Undang-Undang Nomor 40 Tahun 2004 yaitu program Jaminan Kesehatan bagi BPJS Kesehatan dan program lainnya diserahkan ke BPJS Ketenagakerjaan. Kendala-kendala yang sering dihadapi Rumah Sakit dalam memberikan pelayanan kesehatan kepada peserta BPJS adalah masih belum terpenuhinya sarana dan prasarana sesuai dengan standar yang 
Fitriah, Perlindungan Hukum Terhadap Pasien Badan Penyelenggara Jaminan Sosial dalam Mendapatkan Pelayanan Kesehatan, Halaman 223-233

berlaku seperti ruangan, kelas, tempat tidur, alat kesehatan dan pelayanan penunjang lainnya karena keterbatasan dana yang ada. Selain itu juga, masih belum terpenuhinya/tersedianya obat dan bahan medis habis pakai yang dibutuhkan.

\section{DAFTAR PUSTAKA}

Ahmad Miru dan Sutarman Yodo, Hukum Perlindungan Konsumen, Jakarta: $\quad$ PT. Raja GrafindoPersada, 2007.

Amri Amir, Bunga Rampai Hukum Kesehatan, Medan: Woya Medika, 1997.

Bahder Johan Nasution, Hukum Kesehatan Pertanggungjawaban Dokter, Bandung: Rineka Cipta, 2005.

Celina Tri Siwi Kristiyanti, Hukum Perlindungan Konsumen, Jakarta: Sinar $\quad$ Grafika, 2008.

Hendrik, Etika dan Hukum Kesehatan, Jakarta , 2013.

Kertonegoro S, Hukum Asuransi

Indonesia, Bandung: PT. Citra

Aditya Bakti, 1999.

Muhamad Sais Is, Pengantar Ilmu Hukum, Jakarta: PT. Kharisma Putra Utama, 2015.
Sri Praptianingsih, Kedudukan Hukum Perawat Dalam Upaya Pelayanan Kesehatan di Rumah Sakit, Jakarta: Raja Grafindo Persada, 2005.

Sudikno Mertokusumo, Mengenal Hukum Suatu Pengantar, Yogyakarta:

Liberty, 1985.

Soekidjo Notoatmodjo, Etika Hukum dan Kesehatan, Jakarta: PT Rineka Cipta, 2010.

Sofyan Lubis, Mengenal Hak Konsumen dan Pasien, Yogyakarta: Pustaka Yustisia, 2009.

Sendra Ketut, Konsep dan Penerapan Asuransi, Yogyakarta : PPM, 2004.

Subekti, Hukum Perjanjian, Bandung: PT Intermasa, Bandung, 1990.

Titon Slamet Kurnia, Hak atas Derajat Kesehatan Optimal sebagai HAM diIndonesia, Bandung: Alumni, 2007.

Yusuf Shofie, Perlindungan Konsumen dan Instrumen-Instrumen Hukumnya, Bandung: Citra Aditya Bakti, 2009.

Undang-Undang Negara Republik Indonesia Nomor 24 Tahun 2001 tentang Badan Penyelenggara Jaminan Sosial. 